\title{
Design and Analysis of Connecting Rod using Finite Element Analysis
}

\author{
Swapnil. J. Patil ${ }^{1}$, Nihal Mulla ${ }^{2}$, Swapnil Yadav ${ }^{2}$, Niraj Sawant ${ }^{2}$, Sagar Pote ${ }^{2}$ \\ Asst Prof, Mechanical Engineering Department, AGTI'S, Dr. Daulatrao Aher College of Engineering, Karad, India ${ }^{1}$ \\ UG Student, Mechanical Engineering Department, AGTI'S, Dr. DaulatraoAher College of Engineering, Karad, India ${ }^{2}$
}

\begin{abstract}
The connecting rod is the intermediate member between the piston and the Crankshaft. Its primary function is to transmit the push and pull from the piston pin to the crank pin, thus converting the reciprocating motion of the piston into rotary motion of the crank. Connecting rod design is very important because of its role in the crank mechanism, so that the research that can be applied in optimal design of connecting rod can lead to increased engine performance. The connecting rod is very hard and strong but sometimes deforms and breaks due to vibration. The determination the natural frequency of components is essential to prevent the resonance phenomenon. Identify the critical velocity of connecting rod for the resonance frequency range is essential. This study incorporates FEA modal analysis and experimental modal analysis of connecting rod. A parametric model of Connecting rod is modelled using Pro-E and finite element analysis is carried out by using ANSYS Software. Finite element method is used to determine natural frequencies of a connecting rod
\end{abstract}

Keywords: Connecting Rod, crank Mechanism, Natural Frequency, Noise and Vibration, ANSYS Software.

\section{INTRODUCTION}

The connecting rod is the intermediate member between the piston and the Crankshaft. In a reciprocating engine, the connecting rod connects the piston to the crank or crankshaft. Together with they form a simple mechanism that converts reciprocating motion into rotating motion. As a connecting rod is rigid, it may transmit either a push or a pull and so the rod may rotate the crank through both halves of a revolution. Generally connecting rods are manufactured using carbon steel and in recent days aluminium alloys are finding its application in manufacturing of connecting rod. The connecting rod primarily undergoes tensile and compressive loading under engine cyclic process. The forces acting on connecting rod are forces due to maximum combustion pressure and force due to inertia of connecting rod and reciprocating mass. The connecting rod is very hard and strong but sometimes deforms and breaks due to vibration. The determination the natural frequency of components is essential to prevent the resonance phenomenon. Identify the critical velocity of connecting rod for the resonance frequency range is essential.

Vibration is a mechanical phenomenon whereby oscillations occur about an equilibrium point. The oscillations may be periodic, such as the motion of a pendulum - or random, such as the movement of a tire on a gravel road. There are generally two categories for the vibrations the free vibrations and forced vibrations, free vibrations occur when the system is under the action of oscillating systems and their inherent forces external forces there are controversial.All systems that have mass and elasticity can be whit free vibrations, the vibrations that occur in the absence of external stimulus.Vibrations that occur under controversial foreign forces are called forced vibrations, when the controversial operating system is oscillating with frequency, oscillation can be controversial if the impulse frequency of the system natural frequency is resonance mode occurs and may be dangerous, there are large fluctuations.

Natural frequency is the frequency at which a system tends to oscillate in the absence of any driving or damping force. Free vibrations of an elastic body are called natural vibrations and occur at a frequency called the natural frequency. Natural vibrations are different from forced vibrations which happen at frequency of applied force (forced frequency). If forced frequency is equal to the natural frequency, the amplitude of vibration increases manifolds. This phenomenon is known as resonance.

Numbers of methods are available for the design optimization of structural system and these methods are based on mathematical programming technique and optimally designed using ANSYS software. The finite element method is capable of providing this information but it is time taken, the time need to create such a model is large. In order to reduce the modelling software can be used. One such model is provided by ANSYS work bench.

\section{PROBLEM DEFINITION}

The connecting rod is under tremendous stress from the reciprocating load represented by the piston, actually stretching and being compressed with every rotation, and the load increases as the square of the engine speed increase. Combination of axial and bending stresses act on the rod in operation. The axial stresses are product due to 
IARJSET

cylinder gas pressure and inertia force arising on account (A) Small End of Connecting Rod: of reciprocating motion. Whereas bending stresses caused Let, due to centrifugal effects hence it causes failure of $\mathrm{d}_{\mathrm{pi}}=$ inner diameter of small end,mm connecting rod. In some cases there are geometrical errors, $\mathrm{d}_{\mathrm{po}}=$ outer diameter of small end,mm deflections and friction present, and accordingly, =diameter of piston pin, $\mathrm{mm}$ connecting rod some- times creating noise and vibration to =width of small end,mm such an extent that it becomes a problem.

Hence in the machine element like connecting rod according to their geometry errors, unsuitable material selection, deflection and friction present, and sometime applied force and boundary condition create noise and vibration a of element and also reduce life of element.

\section{III.THEORETICAL DESIGN}

1)Design of cross-section of connecting rod:

The cross-section selected is I-section, as shown in fig.

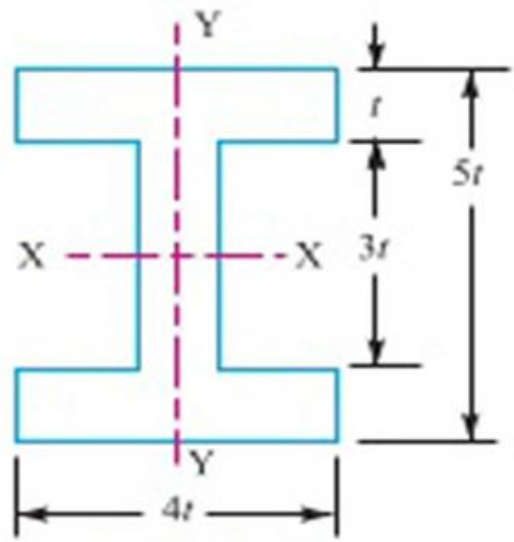

Figure1. I-Section of connecting Rod

Dimensions of cross-section of connecting rod:

Flange thickness $=\mathrm{t}=4.6 \mathrm{~mm}$

Web thickness $=\mathrm{t}=4.6 \mathrm{~mm}$

Width of Flange $(B)=4 \mathrm{t}=18.4 \mathrm{~mm}$

Depth of Section $(\mathrm{H})=5 \mathrm{t}=23 \mathrm{~mm}$

This cross-section is taken at the middle of the connecting rod.

\section{2) Design Of Other Parts Of Connecting Rod:}

The other parts of the connecting rod are:

Small End of Connecting Rod

Big End of Connecting Rod

Bolts for Big End Bearing Cap

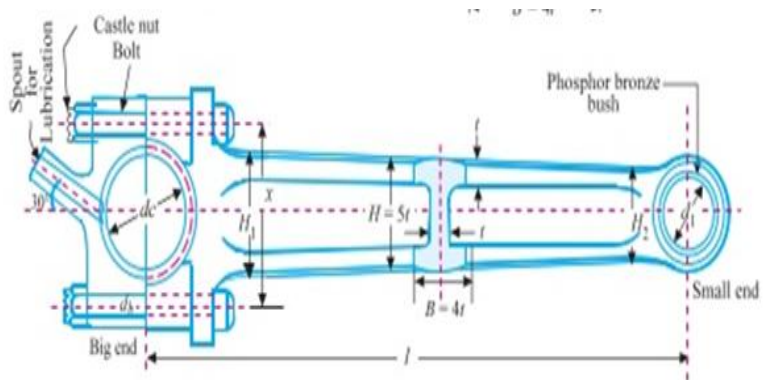

Figure 2.Schematic Diagram of Connecting Rod

$$
\begin{aligned}
& \mathrm{F}_{\text {imax }}=\mathrm{m}_{\mathrm{r}} \mathrm{w}^{2} \mathrm{rcos} \theta+\frac{\cos 2 \theta}{\mathrm{n}_{0}} \\
& =\mathrm{m}_{\mathrm{r}} \mathrm{w}^{2} \mathrm{r}\left[\cos (360)+\frac{\cos (720)}{\mathrm{n}_{0}}\right]\left(\text { at } \theta=360^{\circ}\right. \\
& \mathrm{F}_{\mathrm{imax}}=\mathrm{m}_{\mathrm{r}} \mathrm{w}^{2} \mathrm{r}\left[1+\frac{1}{\mathrm{n}_{\mathrm{e}}}\right] \ldots \\
& \sigma=\frac{F_{\text {imax }}}{\left(d_{\text {po }}-d_{p i}\right) l_{l}}
\end{aligned}
$$

$\mathrm{d}_{\mathrm{pi}}=\mathrm{d}_{\mathrm{p}}+2 \times$ thickness of bearing bush

Inner diameter of small end $\left(\mathrm{d}_{\mathrm{pi}}\right)=36 \mathrm{~mm}$

Outer diameter of small end $\left(\mathrm{d}_{\mathrm{po}}\right)=60 \mathrm{~mm}$ Diameter of piston pin $\left(d_{p}\right)=30 \mathrm{~mm}$

Width of small end $\left(l_{1}\right)=45 \mathrm{~mm}$

\section{(B) Big End of Connecting Rod:}

Let,

of crank pin, $(\mathrm{mm})$

$\mathrm{d}_{\mathrm{cp}}=$ diameter

diameter of the big end of connecting $\operatorname{rod},(\mathrm{mm})$

$\mathrm{d}_{\mathrm{ci}}=$ inner $\mathrm{d}_{\mathrm{co}}=$ outer diameter of the big end of connecting rod,(mm)

$\mathrm{t}_{\mathrm{bc}}=$ thickness of bearing cap, $(\mathrm{mm})$

$l_{\mathrm{bc}}=$ width of the big end of connecting rod,( $\left.\mathrm{mm}\right)$ cap, (mm)

$\mathrm{S}=$ distance between bolt centers of bearing

$$
\mathrm{F}_{\text {max }}=\mathrm{l}_{\mathrm{bc}} \mathrm{d}_{\mathrm{cp}} \mathrm{P}_{\mathrm{b}}
$$

Where, $\mathrm{P}_{\mathrm{b}}=$ permissible bearing pressure between the crank pin and the connecting rod bearing

' $l_{b c}$ ' is taken as,

$$
l_{b c}=(1.0 \text { to } 1.5) \mathrm{d}_{\mathrm{cp} .}
$$

$\mathrm{d}_{\mathrm{ci}}=\mathrm{d}_{\mathrm{cp}}+2 \times$ thickness of bearing shell

$\mathrm{d}_{\mathrm{co}}=\mathrm{d}_{\mathrm{ci}}+2 \mathrm{t}_{\mathrm{bc}}$

$d_{c o}=d_{c i}+2 t_{b c}$

$\mathrm{d}_{\mathrm{cp}}=36 \mathrm{~m}$

$\mathrm{d}_{\mathrm{ci}}=42 \mathrm{~mm}$

$\mathrm{d}_{\mathrm{co}}=70 \mathrm{~mm}$

$12 \mathrm{~mm}$

$$
\mathrm{S}=63 \mathrm{~mm}
$$$$
1_{\mathrm{bc}}=45 \mathrm{~mm}
$$

$\mathrm{t}_{\mathrm{bc}}=$

(C)Bolts for big end bearing cap:

$$
F_{\text {imax }}=2 \times \frac{\pi}{4} d_{\mathrm{e} \times \sigma_{\mathrm{tb}}}^{2} \text { (for two bolts) }
$$

Core diameter of bolt $\left(\mathrm{d}_{\mathrm{c}}\right)=6.68 \mathrm{~mm}$

Nominal diameter of bolt $\left(\mathrm{d}_{\mathrm{b}}\right)=8 \mathrm{~mm}$

\section{IV.EXPERIMENTAL MODAL ANALYSIS}

Experimental modal analysis of a system, deals with determination of natural frequencies, damping ratios, and mode shapes through the vibration testing. In the case of forced vibration, the analysis includes the study of acceleration, velocity and displacement responses of the systems. The basic ideas involve in model analysis are 
IARJSET

then structure or machine or any system is excited its response exhibits a sharp peak at resonance when the forcing frequency is equal to its natural frequency.

\section{1) Steps to follow:}

a) The geometry of the connecting rod to be analysed is imported from solid modeller Pro- Engineer in IGES format this is compatible with the ANSYS[11].

b) The element type and materials properties such as Young's modulus and Poisson's ratio are specified.

c) Meshing the three-dimensional model.

d) The boundary conditions and external loads are applied.

e) The solution is generated based on the previous input parameters.

f) Finally, the solution is viewed in a variety of displays.

\section{2) Analysis of Model:}

behaviour by dividing the geometry into a number of elements of standard shapes, applying constraints. Uses of proper boundary conditions are very important since they strongly affect the results of the finite element analysis. Connecting rod is modelled in Pro-E. The step file of model is imported in ANSYS workbench. The main objective of this work is to perform the Finite Element Analysis of intermediate connecting rod using CAE Tools, so as to determine the natural frequency in the connecting rod. The material properties are demanded in CAE to perform analysis.

2.1 Pre-processing: The constructs a model of the connecting rod in which the geometry is divided into a number of discrete sub regions, or "elements," connected at discrete points called "nodes." Certain of these nodes will have fixed displacements, and others will have prescribed loads.

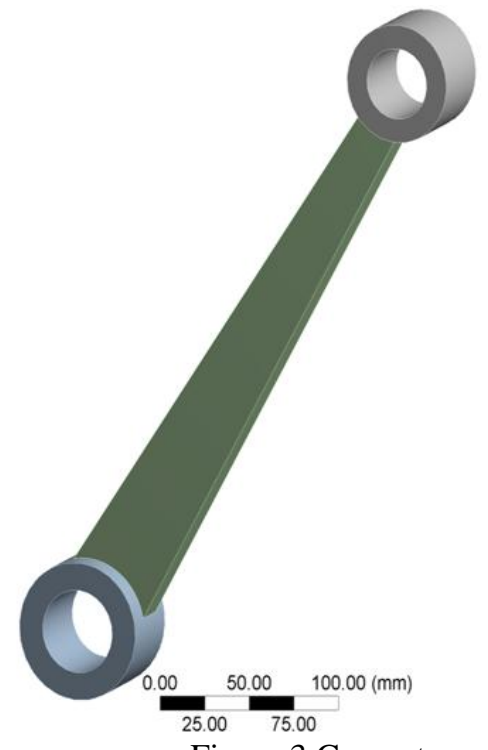

Figure 3.Geometry

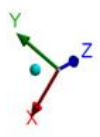

Discretization is the method of converting continuous models to discrete parts.

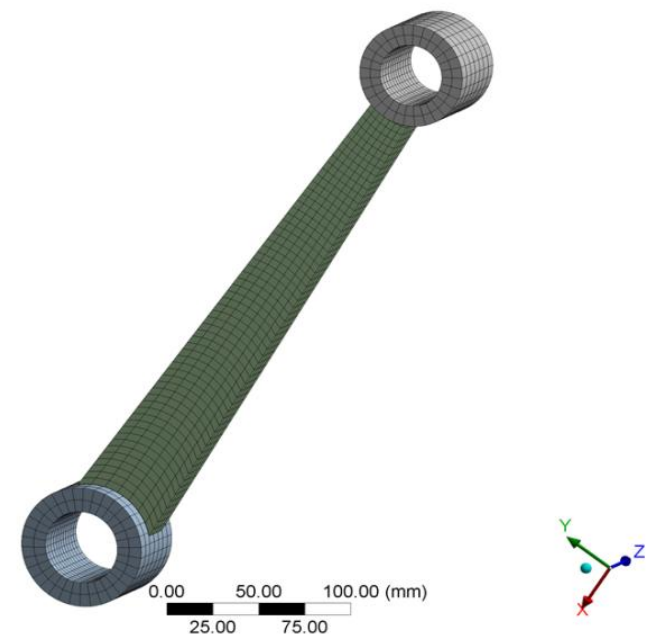

Figure 4. Meshing

2.2 Solution:Solution Part involves declaration of the Analysis type, location of forces and fixation of model.
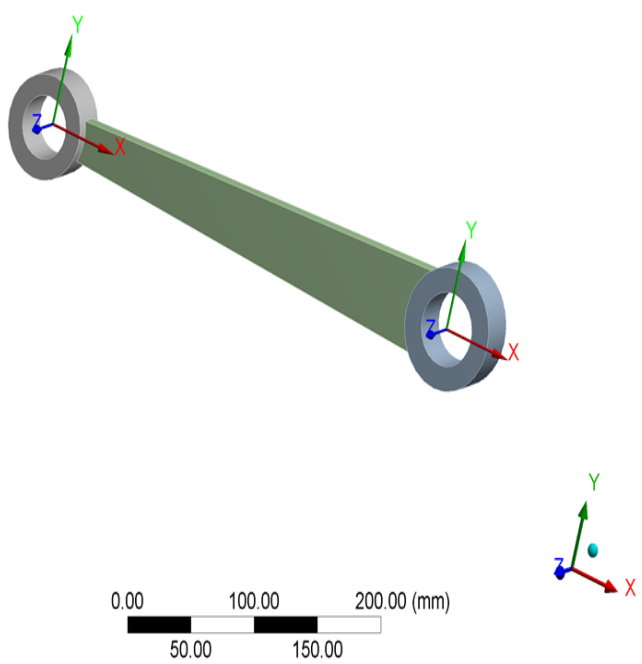

Figure 5.Location of force applied

Pressure: 13. MP
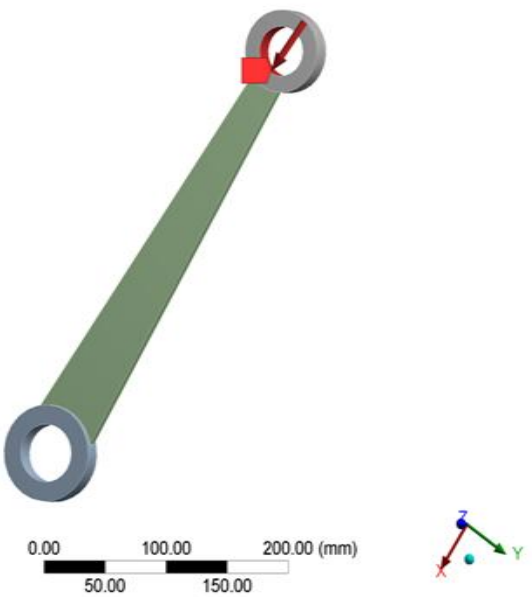

Figure.4. location of pressure 
IARJSET

International Advanced Research Journal in Science, Engineering and Technology

National Conference on Design, Manufacturing, Energy \& Thermal Engineering (NCDMETE-2017)

AGTI's Dr. Daulatrao Aher College Engineering, Vidyanagar Extension, Karad

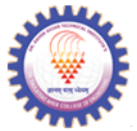

Vol. 4, Special Issue 1, January 2017

Fixed Support
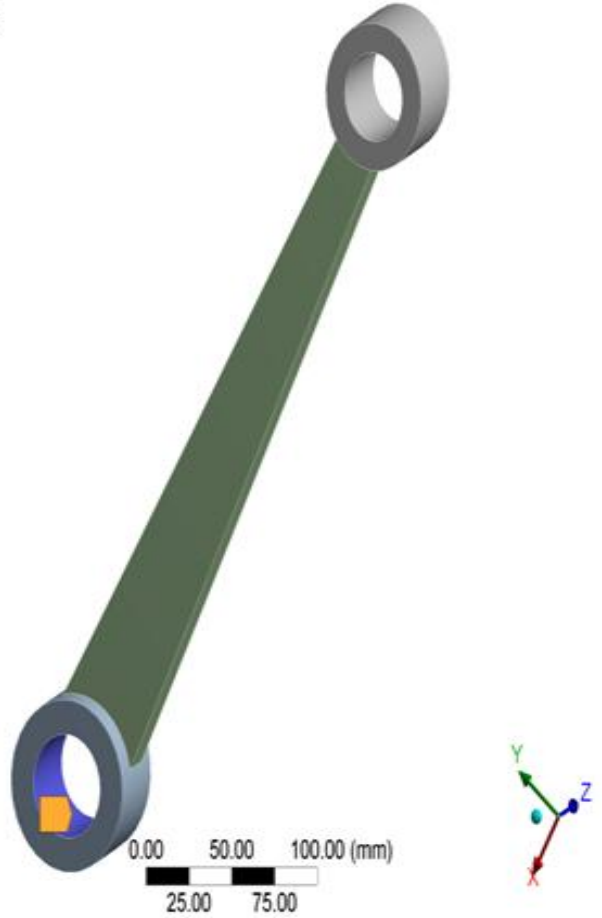

Figure 5. Location of fixed support

2.3 Post Processing: The post processing stage involves viewing of data files generated by the softwareduring the solution phase.

\subsubsection{Result obtain from ANSYS:}

Case: Pressure 13 MPaAt Small End of Connecting Rod

\section{Equivalent (von-Mises) Stress}

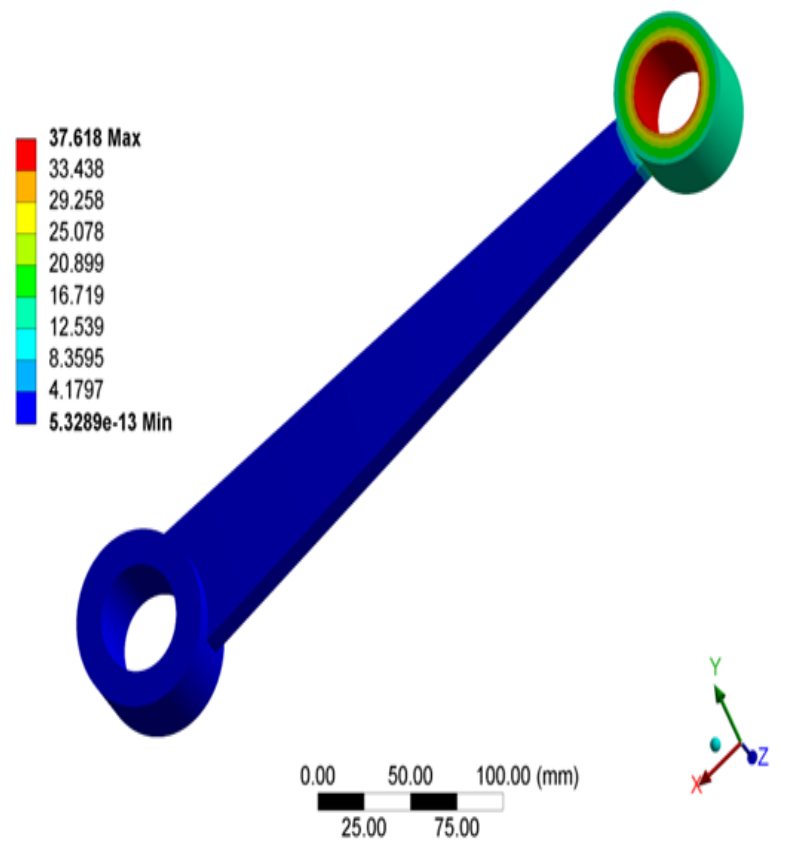

Fig.5.Equivalent Von-Misses Stress (in MPa)

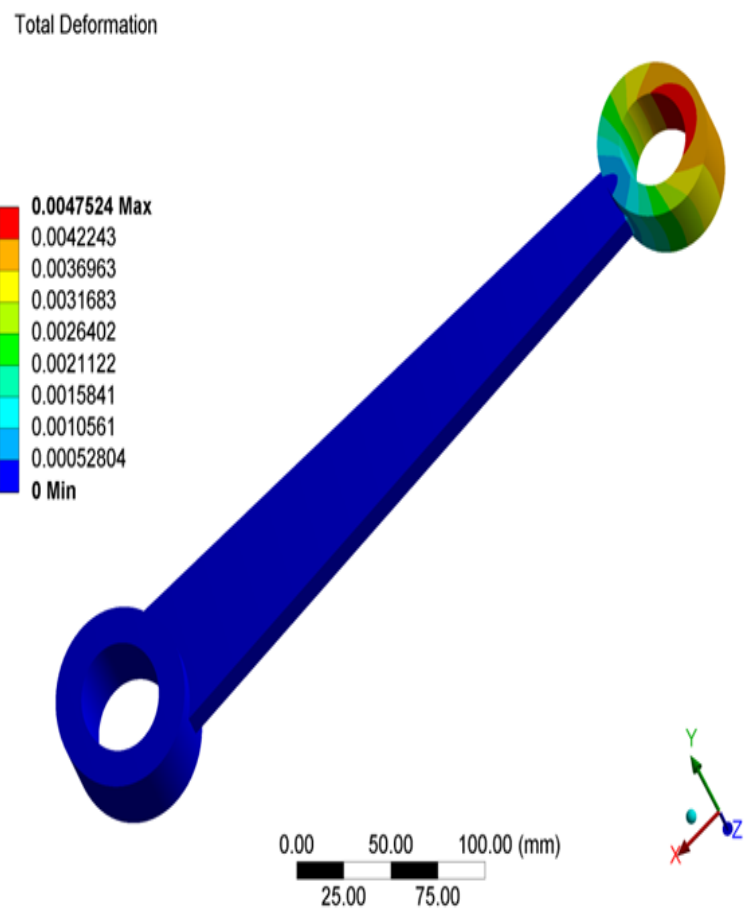

Fig.6.Total deformation (in m)

\section{RESULTS AND DISCUSSION}

Connecting rodundergoes noise and vibration frequently. The maximum voinmises stress generated is $37.618 \mathrm{Mpa}$ and the maximum deformation generated is 0.0047524 $\mathrm{mm}$. The results obtained are within limits and will have minimum effect on the working condition of the shaft and gear. The material used and the design developed for the required force is valid for the automobile connecting rod.

\section{VI.CONCLUSION}

The finite element method (FEM) is most widely for Natural frequency analysis of machine elements using the ANSYS software. The development off finite element analysis model of the shaft with gear mounting to simulate the von-misses stress calculation and total deformation calculation plays more significant role in the design. FEM methods for calculation of natural frequencies of shaft with gear are described. The connecting rod in PRO-E and analyzed in ANSYS for its natural frequency.

Hence with the help of ANSYS software we find out the total deformation, equivalent stress which is response for noise and vibration of machine element such as connecting rod.

\section{ACKNOWLEDGMENT}

The authors would like to express sincere gratitude to Department of Mechanical Engineering, Dr.DaulatraoAher College Engineering, Karad, Satara, India for their help and support. 


\section{REFERENCES}

[1]. "Investigation of Natural Frequency by FEA Modal Analysis and Experimental Modal Analysis of Connecting Rod",SameerNasirMomin ,R.J.Gawande, International Journal of Innovative Research in Science, Volume :5,issue :1,pages 305-310, ISSN(Online): 2319-8753 ,ISSN (Print): 2347-6710, Januray 2016.

[2]. "Analysis of Connecting Rod Using Analytical and Finite Element Method" Prof. N.P.Doshi, Prof .N.K.Ingole , International Journal of Modern Engineering Research (IJMER), Vol:3, Issue:1,Pages 65-68, ISSN: 2249-6645, Jan-Feb. 2013.

[3]. "FE-Analysis of Connecting Rod of I.C.Engine by Using Ansys for Material Optimization", Mr.J.D.Ramani , Prof. Sunil Shukla , Dr.Pushpendra Kumar Sharma , , Int. Journal of Engineering Research and Applications, Vol: 4, Issue :3,Pages 216-220, ISSN : 2248-9622, March 2014.

[4]. "Modal Analysis of Connecting Rod of Nissan Z24 Engine by Finite Element Method", Journal of Science and today's world, volume: 1, issue: 1, pages 54-58, ISSN 2322-326x,2012.

[5]." Analysis of Connecting Rod under Different Loading Condition Using Ansys Software", Mr. H. B. Ramani, Mr.Neeraj Kumar, Mr.

P. M. Kasundra, International Journal of Engineering Research \& Technology (IJERT), Vol: 1 Issue: 9,Pages 1-5, ISSN: 2278-0181, November- 2012

[6]. "Design Optimization and Analysis of a Connecting Rod using ANSYS",G. Naga MalleshwaraRao, International Journal of Science and Research (IJSR), Volume :2 ,Issue :7,Pages 225-229, ISSN: 2319-7064,July 2013

[7]. "ANALYSIS AND OPTIMIZING CONNECTING ROD FOR WEIGHT AND COST REDUCTION", A.K.Nachimuthu, Marlon Jones Louis , C.Vembaiyan, International Journal of Research and Innovation in Engineering Technology ,Volume: 01 Issue: 01, Pages 1 - 7, ISSN: 2394 - 4854,june 2014.

[8]. " Design Evaluation and Optimization of Connecting Rod Parameters Using FEM" ,Suraj Pal, Sunil kumar, International Journal of Engineering and Management Research,Vol:2, Issue:6, Pages: 2125, ISSN No.: 2250-0758,December 2012.

[9]. "Design and Optimization of Four Wheeler Connecting Rod Using Finite Element Analysis", D.Gopinatha, Ch.V.Sushmab, 4th International Conference on Materials Processing and Characterization, Proceedings 2 ( 2015 ) $2291-2299$.

[10]. "FINITE ELEMENT ANALYSIS OF IC ENGINE CONNECTING ROD BY ANSYS” ,R A Savanoor1, AbhishekPatil, RakeshPatil and AmitRodagi, international journal of mechanical engineering and robotic research, Vol: 3, No:3, Pages 511-516, ISSN 2278 0149 ,July 2014.

[11].“Design of Machine Elements", V. B. Bhandari. Tata Mcgraw Hill Book Company, 2010.

[12]."Machine Design”, R. S. Khurmi and J.K Gupta,TataMcgraw Hill Book Company, 2005. 